\title{
DÍAS DE EMOCIÓN INTENSA. SOBRE EL ENTUSIASMO Y SUS PROPIETARIOS
}

\section{Days of Intense Emotion. On the Enthusiam and its Owners}

\author{
María García Alonso* \\ Fecha de recepción: 09/04/2015 • Fecha de aceptación: 31/05/2015
}

Resumen. El artículo analiza la pugna entre diferentes usos de la retórica emocional aplicados a la difusión y mantenimiento de modelos ideológicos contrapuestos en dos momentos de la historia de España: la Segunda República y la Guerra Civil, por un lado, y los comienzos del segundo milenio, por otro. La emoción propiciada por los fenómenos artísticos - lo que podríamos llamar «fervor laico»- y la derivada de los fenómenos religiosos surgen de las mismas fuentes, pero sirven a diferentes causas y, por lo tanto, son el motor de transformaciones sociales y culturales que, con diferente fortuna, han convivido a lo largo de casi un siglo.

Palabras clave: Segunda República española. Guerra Civil española. Misiones Pedagógicas. Persecución religiosa. Transición política española.

Abstract. The article analyzes the struggle between different uses of emotional rhetoric applied to the dissemination and maintenance of opposing ideological models in two moments in the history of Spain: the Second Republic and the Civil War, on one hand, and the beginning of the second millennium, on the other. The excitement arising from artistic phenomena - what we might call "secular fervor»- and religious phenomena, while they may emerge from the same sources, serve different causes and, therefore, are the engine of social and cultural transformations that, with different degrees of success, have continued for nearly a century.

Keywords: Spanish Second Republic. Spanish Civil War. Pedagogical Missions in Spain. Religious persecution. Spanish political Transition.

Estamos viviendo días de epopeya, días de emoción intensa, en los que se escriben con sangre gloriosas páginas de nuestra Historia Patria. ${ }^{1}$

${ }^{1}$ C. Salvador, «Labor de formación social en la Escuela», Boletín de Educación de Burgos, 2. ápoca, I (1936): 17.

* UNED. Dpto. de Antropología Social y Cultural. Edificio Humanidades. Despacho 112. Paseo Senda del Rey, 7. 28040 Madrid. España. mgarciaal@fsof.uned.es

Cómo citar este artículo: García Alonso, María. «Días de emoción intensa. Sobre el entusiasmo y sus propietarios», Historia y Memoria de la Educación, 2 (2015): 73-96. 
Revolución y emoción son dos palabras que inevitablemente van de la mano. Revolución y educación también. En este triángulo (revolución-educación-emoción) los conceptos se apoyan los unos en los otros como un trípode. La emoción, que es toda aquella actividad del espíritu que mueve a la acción fuera de uno mismo, es el motor de cualquier acto revolucionario. El odio, el miedo, la exaltación, la ira, el amor, la salvaje alegría de la victoria o la tristeza feroz de la derrota se combinan en los campos de batalla, se alían con las conspiraciones para conseguir elevar a la categoría de Gobierno lo que hasta el triunfo de una ideología política sólo es una de las facciones en conflicto. Nadie da su vida voluntariamente por ninguna causa que no le provoque una honda conmoción.

Pero esta fusión arrolladora no dura para siempre. Se relaja en cuanto las transformaciones sociales o políticas dejan de ser perturbadoras para convertirse en la realidad cotidiana de la existencia. Es entonces cuando la educación surge como la única posibilidad viable de perpetuación del nuevo estado de las cosas. Y los recursos emotivos, ya cuidadosamente dosificados, entran de nuevo en el juego de la política comunicativa retroalimentando cada causa y aportando un plus de valor a las enseñanzas que de otro modo resultarían estériles.

Si bien la retórica emocional utiliza recursos muy semejantes para fortalecer la lealtad en los distintos sistemas políticos, cada uno de ellos la emplea de un modo que le es propio. Este texto es una reflexión sobre la pugna entre algunos de esos modelos en dos momentos en la historia de España: el período de la Segunda República y los comienzos del segundo milenio de nuestra era.

El motivo de la elección de estos dos períodos no es arbitrario. En ambos momentos se han producido reformas educativas que han utilizado recursos emocionales para ganar el terreno ideológico. En el primero de los casos, fueron empleados para garantizar la adhesión a un nuevo orden republicano que necesitaba reforzar el laicismo para, entre otras causas, fortalecer la separación entre la Iglesia y el Estado. Para ello, al igual que se hizo en otros procesos revolucionarios anteriores (especialmente durante las revoluciones rusa y mexicana, que en cierta medida sirvieron de inspiración al Gobierno español) era necesario despertar en el pueblo lo que podríamos llamar «el fervor laico» o «la emoción de la cultura». La poesía, el arte, la literatura, la música transmitidos a través de las escuelas y de otros movimientos educativos no formales, como las Misiones Pedagógicas, 
alentaban una nueva sensibilidad y marcaban un nuevo ritmo ritual, ligado a las festividades laicas y al disfrute privado en los hogares, usando unas estrategias muy semejantes a las que tradicionalmente había recurrido la Iglesia católica: apropiación de los espacios públicos para el adoctrinamiento, embellecimiento del mensaje para que fuera más atractivo, conversión de ciertos espacios en templos donde se transmite la verdad revelada, etc. Es decir, mediante la creación de mitos asociados a procesos rituales que se desarrollaban fundamentalmente en las escuelas. Mientras esto se producía, la Iglesia católica acentuó también su labor evangelizadora para paliar de algún modo esta pérdida de poder simbólico, pero en estas pugnas el apoyo estatal resulta imprescindible para propiciar cauces de comunicación y, con altibajos entre los años 1931 y 1936, el mensaje republicano fue difundido con bastante éxito, un éxito que cesó bruscamente al fin de la Guerra Civil.

El segundo escenario, en cierto sentido inversamente proporcional al anterior, muestra una similar lucha - pero en este caso de la curia católica- por ganar un terreno ideológico que la democracia le había quitado, al haber efectivamente separado los ámbitos de la religión y el Estado. Se muestra en el texto la evolución que ido teniendo este proceso desde la Transición al presente, pasándose de una cierta "mala conciencia» por el apoyo al régimen franquista — que queda reflejada en resoluciones de la Conferencia Episcopal de los años ochenta- a un enfrentamiento frontal entre dos modos de concebir las relaciones sociales: el «relativista» que surge del derecho democrático a la libre opinión y actuación individual dentro de los cauces de la ley (que por ejemplo despenaliza el aborto o permite el matrimonio homosexual, ante la tolerancia de parte del catolicismo practicante, que lo legitima como parte de la vida privada de los ciudadanos), y el «martirial», que implica un compromiso con el modo católico de vivir y una lucha activa por su implantación en la sociedad, tomando como modelo a los religiosos asesinados durante la guerra (capaces de renunciar hasta a la propia vida por defender sus ideales). Esta «nueva cruzada» pretende animar la empatía con los que sufrieron por su fe acercándola a los más pequeños a través de materiales didácticos e historietas ejemplarizantes.

No tenemos todavía la distancia histórica suficiente para saber cómo va a afectar esta lucha ideológica en el terreno de la educación. Por eso, lo que aquí se pretende es apuntar en algunas pinceladas las líneas de actuación ideológica, utilizando el recurso de las citas literales que muestran las palabras en la voz de sus propios actores. 


\section{FERVORES LAICOS Y OTRAS CONFUSIONES DEL ESPÍRITU}

El gusto de aprender a través de la experiencia, la curiosidad por descubrir, serían quizás las principales aportaciones de Manuel B. Cossío a la Institución Libre de Enseñanza, y con ello a la historia de la pedagogía contemporánea. La función del maestro no consistiría tanto en transmitir una sabiduría enciclopédica sino en «enseñar a ver». Para el que no sabe ver, las cosas

están muertas, y hay que darles vida. Le son indiferentes, y es necesario que lo soliciten; mudas, y deben decirle algo; cerradas, y hay que darle la llave para abrirlas, porque ellas, que no son en sí muertas, ni indiferentes, ni mudas, que no conceden tampoco sus favores caprichosamente, que a todos llaman con el mismo cariño, esperan siempre pacientes a que la venda se les caiga de los ojos para revelarles hasta su fondo íntimo. ${ }^{2}$

En la época en que el joven Cossío escribía estas palabras, en 1879, bastante más de la mitad de los españoles eran analfabetos. España estaba a punto de perder sus colonias y se hundía en un marasmo económico y político. En las aldeas los maestros, mal preparados y peor pagados, dependían para su subsistencia de la caridad de los vecinos ya que los responsables de sus gastos eran los empobrecidos ayuntamientos. Las escuelas se improvisaban en locales lóbregos, sin iluminación ni ventilación, huyendo del frío del invierno o de los rigores del sol. Dentro del orden social era considerado un gasto superfluo e incluso pernicioso el dedicado a cualquier educación que se extendiera a las clases trabajadoras, campesinas u obreras, más allá de los rudimentos básicos que les permitieran cumplir con sus funciones. En aquel contexto las afirmaciones de Cossío sonaban a revolución:

El niño de la ciudad tiene, señores, el periódico, el teatro, la conversación culta de la atmósfera que le rodea, los museos, una exposición permanente en los escaparates de cada tienda; pero el pobre niño del campo, ¿dónde puede ver jamás una estatua? ¿Quién le dirá que ha habido un Shakespeare o un Velázquez? ¿Quién le hará sentir la belleza de una melodía de Mozart, de una estrofa de Calderón o un Eco Nacional de Ruiz Aguilera? ¿Quién le excitará a que levante sus ojos de esa tierra que fecunda quizás ya al lado de sus padres?

\footnotetext{
${ }^{2}$ Manuel B. Cossío, «Carácter de la Pedagogía contemporánea. El arte de saber ver», Boletín de la Institución Libre de Enseñanza, 65 (1879):154.
} 
¿Quién le instará para que piense, reflexione sobre algo que no sea corporal, ni quien le llamará la atención jamás sobre el placer que de la reflexión resulte? ${ }^{3}$

Será cincuenta años más tarde cuando un anciano Cossío presida el más original proyecto de extensión cultural del siglo, las Misiones Pedagógicas de la Segunda República, con el objetivo de paliar esa desigualdad en las emociones. Esta iniciativa vendría a cumplir el artículo 48 de la Constitución republicana de 1931, aún antes de ser promulgada: ${ }^{4}$

El servicio de la cultura es atribución esencial del Estado, y lo prestará mediante instituciones educativas enlazadas por el sistema de la escuela unificada. [...] La República legislará en el sentido de facilitar a los españoles económicamente necesitados el acceso a todos los grados de enseñanza, a fin de que no se halle condicionado más que por la aptitud y vocación.

El principal cauce que tenía el Gobierno republicano para crear lazos emotivos con la nueva estructura de un Estado laico y democrático era la instrucción pública. Si las parroquias eran los centros neurálgicos que gestionaban el reino de Cristo — que en España se superponía simbólicamente al reino del monarca Alfonso XIII ${ }^{5}$ - , las escuelas fueron convertidas en los focos de difusión de una nueva idea de ciudadanía, que tenía que enraizarse en las mentes más jóvenes con unos argumentos dirigidos más a los corazones que a los cerebros. Significaba el cambio no solo de un concepto patrimonial a otro universalista de educación, sino también el uso del poder evocador del arte - especialmente de un arte popular y social_ para despertar un tipo de entusiasmo inédito fuera de los púlpitos: lo que podríamos llamar el gozo de la cultura. La inversión realizada -ingente si comprobamos las cifras de creación de bibliotecas y escuelas - apoya la idea de que nos encontramos ante un problema que era pensado como de gran relevancia. Sin embargo, los esfuerzos propagandísticos no resultarían exitosos hasta que no se asociaron al esfuerzo bélico. Y entonces fue, a todas luces, demasiado tarde.

\footnotetext{
${ }^{3}$ Manuel B. Cossío, De su jornada (fragmentos), (Madrid: imprenta de Blass S.A., 1929), 215. Discurso de Cossío en el Congreso Nacional Pedagógico de 1882.

${ }^{4}$ Las Misiones fueron creadas en mayo de 1931 y no sería hasta diciembre de ese año que se aprobaría la nueva Constitución.

${ }^{5}$ Véase el apartado «Lealtades patrióticas» del artículo de María García Alonso, «Las regiones», Revista Anthropos, 227 (2010): 163-176.
} 
Las Misiones Pedagógicas se posicionaron desde su creación como una alternativa de emoción laica frente a las otras misiones religiosas, que habían intensificado su labor evangelizadora en estos años en los que la Iglesia sentía amenazada su existencia. Por ello aquéllas eran vistas por los sectores más conservadores como competidoras directas en el terreno moral y no escatimaron esfuerzos para impedir su desarrollo. Pero tampoco eran bien consideradas por algunos intelectuales como José Bergamín, que le reprochaba su falta de compromiso político, su inutilidad práctica. Sonrisas robadas, rostros fascinados ante las imágenes en movimiento o ante la carne pintada de los cuadros; pastores con la zamarra llena de aventuras en los mares del Sur: éstas eran sus grandezas pero también sus debilidades. Cómo escribía Bergamín en 1933 en Cruz y Raya,

¿basta al hambre y sed de justicia popular, que es hambre y sed de espíritu, hambre y sed de veras - las que se revelan en esos rostros-, esta propaganda seudo-religiosa, esta mixtificación pedantesca, bautizada corroborativamente en este sentido, con el nombre de Misión Pedagógica? ¿No será esta misión pedagógica, como la otra, la antipedagógica, la de las razzias, en la propaganda de la vacua, irresponsable actitud gubernamental del Estado, un pilatesco afán escénico de lavarse las manos ante la sangre? ${ }^{6}$

Otros, como Manuel Abril, representante de la Sociedad de Artistas Ibéricos, censuraban su sentido estético simplificador:

A los chicos que nunca oyeron ni vieron otra cosa que lo más elemental de su rincón aldeaniego, se les da la quintaesencia de cultura. Esto nos parece a nosotros un grave error desde varios puntos de vista. El rudimentario espíritu de un rapaz aldeaniego no comprende ni puede comprender, y hasta diríamos no debe comprender, las excelencias del Greco. Enseñar eso a los chicos puede ser tiempo perdido. Y puede ser peor: puede conseguirse con eso que algunos crean que entender lo que no entienden y crean entenderlo por haber sido explicado con falsa explicación. De ahí nace la confusión y nace la pedantería. El ciego que cree ver es peor que el ciego mismo. ${ }^{7}$

\footnotetext{
6 José Bergamín, «La letra y la sangre», Cruz y Raya, 1 (1933): 154.

${ }^{7}$ Manuel Abril, «Misiones Pedagógicas», Arte. Revista de la Sociedad de Artistas Ibéricos, II (2), (1933): 27-28.
} 
Esa ceguera fue estimulada por el Museo del Pueblo, la sección misionera más querida por Cossío, porque implicaba llevar los cuadros del Museo del Prado $^{8}$ a pajares y casonas, dejar sus reproducciones en las escuelas y educar fugazmente su mirada para saber ver. En una iniciativa pionera se había constituido un servicio de préstamo de estas láminas, paralelo al de libros de la biblioteca circulante, para que pudieran adornar por un tiempo el lugar principal de los humildes hogares. Y así, coincidían en esas casas campesinas la Maja de Goya con las imágenes religiosas, los clásicos de la literatura con las estampitas de la Virgen. Cuando la guerra acabó con la posibilidad de combinar los mundos de la religiosidad popular y la alta cultura, muchos aldeanos protegieron estas láminas en colores sepia como si de tesoros se tratara porque con ellas creían proteger el patrimonio de la República y las entregaban con delicadeza a los miembros de la Junta de Incautación y Protección del Tesoro Artístico. En la era de la reproductibilidad técnica, a la que Walter Benjamin achacaba la pérdida del aura de la obra de arte - ese «valor único e insustituible de la obra de arte auténtica» ${ }^{9}$ - , las copias habían asumido, gracias al poder simbólico de la cultura entregada a los ojos nuevos de los campesinos españoles, la misma eficacia que los originales.

El choque de impresiones encontradas que se produjo en cerca de 6.000 pueblos de España con la llegada de los misioneros fue vivido por las dos partes, emisores y receptores del mensaje cultural, como el encuentro entre dos mundos que existían ignorándose mutuamente. Los informes que salpican las memorias del Patronato de Misiones nos hablan de ese desencuentro inicial:

La impresión que se recoge de estos pueblos es de que existe en ellos una virginidad, de que se hallan por primera vez ante muchas cosas. Gentes infantiles que ahora despiertan después de un sueño de siglos y para quien es todo inédito, nuevo. Una avidez inmensa de saber, de enterarse de las cosas del mundo y de la vida.

Es de notar el género de ignorancia en que se hallan estos pueblos. Es una ignorancia distinta de la que un observador ingenuo pudiera creer. No se trata de ignorancia de verdades particulares, de falta de

\footnotetext{
${ }^{8}$ Las copias de estos cuadros, de escala semejante a los originales, habían sido pintadas por jóvenes artistas como Ramón Gaya o Eduardo Vicente.

${ }^{9}$ Walter Benjamin, La obra de arte en la época de su reproductibilidad técnica (México D.F.: Ed. Ítaca, 2003), 49.
} 
noticias, de estar enterados al día de acontecimientos más o menos recientes; es algo distinto. Lo que ellos ignoran es toda esa serie de supuestos de nuestra cultura, los cimientos que sustentan y hacen posible nuestro saber. Por eso la primera y más angustiosa impresión que de ellos se recibe es que falta el terreno común para entenderse; que no hay, intelectualmente, convicciones comunes de donde partir.

A falta de terreno común teorético, suple el que sí lo hay sentimental y espiritual. Desde el primer instante hemos sintonizado con ellos; hemos vibrado acorde, hemos sentido junto. Y esta atmósfera cordial es la que hace posible la Misión, la que hace que ellos escuchen atentos y adivinen lo que no entienden y que nosotros intuyamos de qué cosas debemos hablarles y con qué tono, con qué palabras y con qué voz.

Otra nota de extraordinario interés es la situación política. Existe una gran tensión, un vivo apasionamiento en torno a los problemas políticos, sociales y religiosos. Pero, en contra de lo que pudiera creerse en el primer momento, no existe un estado relativamente fijo de opinión, sino un pensamiento exaltado siempre, pero cambiante y contradictorio. La ignorancia mezclada con el apasionamiento (envenenamiento en algunos casos) hace que toda discreción sea necesaria. Y así, al explicarles la película «Granada», que daba motivo para hablar del descubrimiento de América y de la unidad de España, era imposible nombrar a los Reyes Católicos. Tampoco pudimos recitar un romance acerca de la Virgen María, ni fue posible la audición de un disco de Canto Gregoriano. ${ }^{10}$

La falta de dogmatismo convierte a las Misiones Pedagógicas en un fenómeno extraño dentro del panorama internacional, en el que la difusión cultural iba indisolublemente unida a la propaganda siguiendo el ejemplo soviético. Lunacharski, el primer Comisario de los Soviets para la Instrucción Pública, diría:

Si la revolución puede dar al arte un alma, el arte puede darle a la revolución su boca. Conocemos esto perfectamente, y el gran propagandista colectivo, el predicador colectivo que es el Partido Comunista debe proveerse de todos los medios del arte, que de esta forma se convertirá en poderoso sostén de la propaganda. No sólo

${ }^{10}$ Informe sobre la Misión a Navas del Madroño (Cáceres). Memoria del Patronato de las Misiones Pedagógicas (septiembre 1931- diciembre 1933) (Madrid, Museo Pedagógico Nacional, 1934), 37. 
las pancartas, sino también, en una forma menos fugaz pero poseyendo más profundas ideas, los cuadros y las esculturas pueden resultar, por así decirlo, el medio patente para la asimilación de la verdad comunista. El teatro ha sido llamado con tanta frecuencia gran tribuna, gran cátedra para la divulgación, que no vale la pena detenernos aquí en esta cuestión. ${ }^{11}$

A pesar de que la fugacidad del paso de las Misiones por los pueblos y la participación en ellas de misioneros de distinto signo político ${ }^{12}$ le restaban operatividad propagandista, lo cierto es que ayudaron a activar un circuito de emociones ligado a un nuevo sentimiento ciudadano, que tenía notorios puntos en contacto con algunos fenómenos religiosos a los que sustituía. En el caso español, como en el del México revolucionario, la competencia entre misiones cristianas y laicas se resolvió en la búsqueda de motores espirituales que activasen una inercia de siglos. En ambos casos, la construcción de escuelas era el símbolo del avance del Estado por el hojaldrado interior de los territorios patrios. Narciso Bassols, Secretario de Instrucción Pública de México entre 1931 y 1934, refiriéndose al impulso dado durante su mandato a la construcción de escuelas rurales que pasaron en tres años de 3.000 a 7.504, dirá que

sin exagerar siquiera levemente el significado de esta cooperación de los indígenas en la creación de las escuelas debo afirmar que desde la época de la colonia española, en que cada pueblo levantaba su iglesia, no se había dado un paso de tanta importancia en la consolidación de la vida comunal del país. Las iglesias en muchas poblaciones han envejecido, se han derrumbado ya por terremotos o abandono, y frente a ellas aparece la casa de la escuela, como centro vivo de la comunidad y núcleo ineludible de su vida futura. Esta actividad no sólo tiene un alcance externo y material, sino que también encarna un hecho psicológico de enorme significación y que debe tomarse en cuenta para comprender las condiciones actuales del campo. Los campesinos han puesto en la escuela su fe, se

\footnotetext{
${ }_{11}$ Anatoli V. Lunacharski, «La revolución y el arte», en Las artes plásticas y la política en la Rusia revolucionaria, (Barcelona, Seix Barral, 1969), 68-70.

12 Pilar Gobernado, que participó en las misiones del Teatro y Coro del Pueblo en el año 1936, comentaba incluso, en conversación mantenida con la autora, que había visto responder a algún compañero con el brazo en alto a los saludos de los falangistas poco antes del comienzo de la guerra. Aunque esta ideología era claramente muy minoritaria en el grupo, esto nos indica que había misioneros de muy distinto signo político unidos por un afán de justicia social.
} 
han agrupado espiritualmente alrededor de ella y están con ella en forma más segura y fecunda, por ser más consciente, que como se agruparon alrededor de las iglesias que los conquistadores les hicieron levantar hace tres siglos.

\section{Aunque el propio Bassols reconocía que}

no hubiera sido posible la creación de las miles de escuelas rurales, por lo menos con esa cooperación tan plena del campesino, si no hubiera coincidido la época del despertar de la educación con un momento de intensa agitación social producida por el hecho de que al mismo tiempo que se estaban creando las escuelas se entregaba la tierra liberando a los peones de su vieja condición de esclavos. ${ }^{13}$

La conversión de todo hombre moderno en un misionero, de todo Estado en servidor y propagador de alguna idea ${ }^{14}$ coincide en el mundo contemporáneo con una sutil infiltración del discurso religioso en la vida política y cultural. Las escuelas se transforman en templos; los intelectuales y artistas, en profetas capaces de despertar un tipo de fervor laico inédito que se despertaba ante los nuevos iconos del sentimiento: las representaciones artísticas. Volviendo de nuevo a México, Daniel Cosío Villegas hablará de la implantación de las misiones culturales mexicanas en términos que podrían haber sido usados para describir semejantes movimientos en la Rusia soviética, ${ }^{15}$ en la España republicana y, tras la Segunda Guerra Mundial, en otros países de América Latina:

La educación no se entendió ya como una educación para la clase media urbana, sino en la forma única que en México puede entenderse: como una misión religiosa, apostólica, que se lanza y va a todos los rincones del país, llevando la buena nueva de que México se levanta del letargo, se yergue y camina. Entonces sí que hubo ambiente evangélico para enseñar a leer y a escribir al prójimo; en-

\footnotetext{
${ }^{13}$ Las citas de Bassols se encuentran en Augusto Santiago Sierra, Las Misiones culturales (1923-1973) (México, Sepsetentas, 1973), 100-101.

${ }^{14}$ Sobre este tema, véase María García Alonso, «Reflexión sobre los medios y los fines: las Misiones Pedagógicas en el contexto internacional», Las Misiones Pedagógicas (1931-1939) (Madrid: Sociedad Estatal de Conmemoraciones Culturales, 2006), 184-208.

${ }^{15}$ No hay que olvidar que Lunacharski pensaba también — como lo haría Benjamin—que la religión era la única fuerza capaz de despertar el entusiasmo en las gentes, y «sin entusiasmo el hombre no es capaz de crear nada grande». La base del comunismo no era otra cosa que el impulso religioso de comunión con la colectividad.
} 
tonces sí que se sentía, en el pecho, y en el corazón de cada mexicano, que la acción educativa era tan apremiante y tan cristiana como dar de beber al sediento o de comer al hambriento. [...] Entonces se tenía fe en el libro de calidad perenne; y los libros se imprimieron a millares y a millares se obsequiaron. Fundar una biblioteca en un pueblo pequeño y apartado parecía tener tanta significación como levantar una iglesia y poner en su cúpula brillantes mosaicos, que anunciaran al caminante lejano la existencia de un hogar donde descansar y protegerse. ${ }^{16}$

Similares alusiones encontraremos en el discurso de Manuel Bartolomé Cossío leído en la primera misión pedagógica a Ayllón (Segovia), en diciembre de 1931: «[Se cumple] además de esta suerte la obra evangélica, no sólo enseñar al que no sabe, dejando un poco de lo que ellos [los habitantes de las ciudades] disfrutan, sino también la de consolar al triste, es decir, de alegrarlo y divertirlo noblemente». ${ }^{17}$

El enfrentamiento entre el modelo del fervor laico y el que hundía sus raíces en la religión podía encontrarse no sólo en las calles, los púlpitos y las escuelas: también se encuentra diseminado en multitud de escritos educativos y doctrinales. Después de haber extendido el cristianismo por toda América, en los años treinta España volvía a ser de nuevo un territorio de misión tanto para el Estado como para la Iglesia. El Gobierno necesitaba impulsar valores de adhesión a sus ideas renovadoras con el mismo tesón que la Iglesia debía impedir que lo hiciera.

Pero con el exilio del monarca el vínculo simbólico que se había mantenido sólidamente fusionado desde la época de los Reyes Católicos, uniendo el catolicismo con el modelo de Estado legítimamente establecido, se estaba viniendo abajo. El discurso patriótico bebía en esos momentos de fuentes muy distintas que las que le habían permitido al cardenal Enrique Roig afirmar en 1930 lo siguiente:

Se han amasado a la vez con los mismos principios, y hasta podemos decir que con la misma sangre, los cimientos de la Religión y la Patria en España. [...] Toda institución representativa de la patria debe reflejar en sí esa quinta esencia o fondo común secular. Y

\footnotetext{
16 Daniel Cosío Villegas, "La crisis de México», Cuadernos Americanos, VI (XXXII), (1949): 46-47.

17 Memoria del Patronato de Misiones Pedagógicas, septiembre de 1931-diciembre de 1933 (Madrid: Museo Pedagógico Nacional, 1934), 15.
} 
ninguna en España, como la Monarquía, especialmente al personificarse en el actual Monarca, lo refleja y patentiza. Unidos como en toda la trama de nuestra Historia, han ido durante el feliz reinado de Alfonso XIII, los sentimientos de Religión y Patria. ${ }^{18}$

Cristo Rey estaba dejando de presidir las aulas, los plenos municipales y los cementerios, y su refugio en conventos y templos ya no era inexpugnable, debido a las oleadas de violentos incendios y expolios de edificios religiosos. No sólo la curia estaba indignada por estos sacrilegios. Los primeros momentos de la Segunda República coinciden con una verdadera epidemia de visiones y profecías. Ya que los símbolos religiosos desaparecían de los espacios públicos antes sacralizados, los fieles buscaron otros espacios, arrancándoselos a terrenos no urbanizados (fuentes, prados, matorrales, etc.) y desplazando los territorios sagrados de los centros urbanos a las periferias para poder construir allí nuevos santuarios. La Virgen se manifestaba en ellos sin intermediarios, especialmente en el norte de España, ${ }^{19}$ quejándose a través de médiums de que el clero no estaba protegiendo debidamente a su familia, la Sagrada Familia, de los desmanes de la izquierda y que esto acarrearía grandes males.

Así la Iglesia, herida institucionalmente, tenía que derrochar esfuerzos para aglutinar a su propio rebaño, fortalecer los lugares de culto consolidados y canalizar esas manifestaciones populares hacia movimientos de tinte político, y para ello andaba a la búsqueda de líderes fuertes que dirigiesen su cruzada. No eran pocos los que entonaban el mea culpa por no haber advertido a tiempo esta necesidad.

Así hemos vivido en España. Sin cabezas o con cabezas desproporcionadas, vacías o ligeras. Improvisábamos, quemábamos en holocausto del egoísmo o cambiábamos de ideal con pequeñeces despreciables. Nuestros templos se llenaban. Nuestros actos públicos se hacían en mosaicos de compactas muchedumbres. Pero las muchedumbres, masa y turba, volvían sobre sus pasos de efímero entusiasmo. Ni una inteligencia preclara y decidida que las guiase,

\footnotetext{
${ }_{18}$ Citado en Luis Cano, «Acerca de Cristo Rey», en Católicos entre dos guerras. La historia religiosa de España en los años 20 y 30, eds. Jaume Aurell y Pablo Pérez López (Madrid: Biblioteca Nueva, 2006), 186.

${ }^{19}$ Especialmente fértil en apariciones fue el pueblo guipuzcoano de Ezquioga, que en los años treinta parecía configurarse como un Lourdes español. Para ahondar en este tema véase el excelente libro de William Christian Jr., Las visiones de Ezquioga. La Segunda República y el Reino de Cristo (Madrid: Ariel, 1997).
} 
ni una voluntad de hierro que contuviese las desbandadas. Las minorías selectas por su inteligencia, por su valor o por su virtud, no existían o no supieron actuar. [...] La muchedumbre, como los mares, es tornadiza y veleidosa, se mueve y remueve al soplo de vientos contrarios. Nos preocupa el porvenir de las Obras Misionales Pontificias. Tenemos masa, necesitamos cabezas directoras. ${ }^{20}$

Tras la sublevación militar del 18 de julio de 1936, se inició una nueva reconquista religiosa de España que se serviría también del entusiasmo para estimular la adhesión de los más jóvenes. Es notable señalar cómo las mismas expresiones que habían sido usadas por los ideólogos de la emoción laica valían también para defender los bienes del fervor religioso. El primer Boletín de Educación de Burgos publicado después del alzamiento da numerosas pruebas del cambio de signo de los tiempos, como se puede observar en los siguientes fragmentos:

Con el pretexto de una falsa solidaridad humana se quiso borrar la fraternidad humana, que es virtud cristiana y española; se sustituyó la caridad con la asistencia social, la Religión con el socialismo, nuestros himnos nacionales con «La Internacional» [...] En aspectos estrictamente educativos, se procuró ahogar las fuentes del sentimiento, tan pegados a nuestro fondo étnico, para reemplazarlos por un cerebralismo seco y propicio a ese fetichismo intelectual que se entronizó como el exponente y el paradigma de una personalidad perfecta. ¿Por qué? Por la única razón de que a los españoles les caracteriza el sentimiento, el carácter, la voluntad y la intuición, con cuyas cualidades fundamentó su genio histórico e hizo una España grande y respetada. Y así, la mayor parte de los libros que cayeron sobre nuestras Escuelas y sobre nuestras Bibliotecas escolares, respondían a esa sequedad, so capa de un estoicismo que no era sino frialdad cuidadosamente estudiada.

Hagamos nosotros nuestra Escuela nueva, jugosa, alegre, fina, sentimental. Eduquemos a nuestros niños en la fortaleza de ánimo y en el vigor de la voluntad; reforcemos las energías de su intuición, dotémosles de un carácter firme e invencible y, sobre todo, impregnémosles, no de religiosidad, sino de los principios de la Religión cristiana. $^{21}$

20 «Editorial», Obra pontificia de la Propagación de la Fe (junio de 1933): 1.

21 O., "Nuestra Escuela nueva», Boletín de educación de Burgos, 2. época, I (1936): 16. 
¡Los afectos! Cuánto no hemos contribuido a estrangularlos en el alma infantil con esa fingida superioridad pedantesca, insensible a toda emoción simplista. Ha estado de moda el no sentir, el no emocionarse como se hizo de mal gusto toda afirmación rotunda, toda espiritualidad idealista. Se motejó de sensiblera toda emotividad apasionada, como se ahogaron las manifestaciones nacionales con el dictado de patrioteras. La España caduca, como todos los viejos, se hizo criticista y el crítico, por naturaleza, rehúye la emotividad que es pasión, que es juventud. España renace y exige almas jóvenes, apasionadas y vehementes. Desecha, Maestro, las prevenciones que almas pobres, apocadas o superfluas infiltraron en tu espíritu al formarlo, y haz de tu escuela un manantial de afectos y no olvides nunca, que si quieres conmover, que si quieres despertar emociones tienes que empezar por emocionarte. ${ }^{22}$

\section{TRANSICIONES A LA ESPAÑOLA EN EL SEGUNDO MILENIO}

Más de setenta años después de estos acontecimientos y tras considerables esfuerzos de reconciliación en la sociedad española, una parte importante de la educación se sigue tejiendo con los mismos mimbres: emoción versus crítica, entusiasmo versus conocimiento. Resultados de estudios recientes sobre el valor de los recursos emocionales en los manuales escolares de la transición democrática nos muestran una cauta contención de los recursos educativos que pudieran estimular sentimientos potencialmente disgregadores de la nueva idea de patria multicultural y tolerante con la diversidad, que ha sido la piedra angular de la convivencia en la Transición. ${ }^{23}$ La misma cautela mostró el episcopado español cuando, en 1985, el papado de Juan Pablo II quiso activar las beatificaciones de mártires católicos de la guerra civil española. La Conferencia Episcopal, entonces presidida por Monseñor Tarancón, aprobó una opinión contraria a esta idea en un pleno en el que ratificaba su compromiso con los valores de la democracia:

Ante el cincuenta aniversario de la Guerra Civil Española, la Iglesia comprometida en la reconciliación de todos los españoles y en la profundización de la democracia, debe potenciar todos los gestos

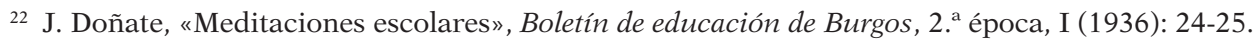

${ }^{23}$ Véanse los resultados del proyecto "Ciudadanía, identidades complejas y cultura política en los manuales escolares españoles (1978-2006)» dirigido por Gabriela Ossenbach (UNED).
} 
que favorezcan este objetivo y criticar aquéllos que lo dificulten. En este sentido, creemos que no es oportuno llevar adelante el proceso de beatificación de los mártires de la Cruzada. ${ }^{24}$

Pero mucho ha llovido desde entonces y el espíritu de contención, que había relegado al olvido algunas justas reclamaciones y opacado poderes que durante al franquismo habían resultado hegemónicos, ha visto despertar a sus fantasmas en este nuevo milenio en los dos terrenos donde la ideología se filtra de modo más contundente en las escuelas: el estudio de la historia del pasado reciente y la enseñanza de la religión.

La tímida irrupción de las voces de las víctimas del conflicto armado a través de los relatos de sus testimonios y las primeras exhumaciones de fosas comunes republicanas con cobertura mediática dieron un giro inesperado a la tranquila inercia de los discursos de consenso que se escondían en los textos escolares. La memoria histórica, que oculta en esta denominación una voluntad expresa de convertirse en explicación autorizada de los hechos vividos, comenzó a infiltrarse en las actividades didácticas que acompañaban a las explicaciones de la Guerra Civil. Siempre resulta menos comprometido para los equipos docentes comenzar delegando en los hogares las explicaciones que se temen expresar en grandes titulares. De este modo, las vivencias de abuelas viudas, de familiares exiliados, de miseria, hambre y cárcel comenzaron a ser expuestas en trabajos y discutidas en grupos de estudiantes. Y con ellas resurgieron sentimientos que poco tenían que ver con la tolerancia: la ira, el asombro, el deseo de venganza, la incomprensión, el anhelo de justicia y reparación de una parte de la sociedad que había sido expulsada de una patria que era la suya, pero que les había sido enajenada.

A medida que este espíritu de reivindicación se fue apoderando de los medios de comunicación, de las ideologías de parte de la clase gobernante, ganando la calle e incluso acercándose, aunque con poca fortuna, a los tribunales penales se fue haciendo también más explícito el dolor de los que perdieron la guerra en los manuales escolares: la pérdida de derechos de las mujeres, la resistencia del maquis, las depuraciones profesionales, los campos de concentración, la emigración forzosa, la carestía de alimentos, las ejecuciones sumarias, etc. Las fotografías de los campos de refugiados espa-

${ }^{24}$ Congreso de Evangelización y hombre de hoy (Madrid: Editorial de la Conferencia Episcopal Española, 1985): 421. Adviértase en todo caso la referencia a la «Cruzada» —guerra entre cristianos e infieles- en la redacción del texto final. 
ñoles en Francia se comparan con las de tantos otros refugiados de distintos países y etnias sentados, esperando sin esperanza, en el suelo de los campamentos del Alto Comisionado de las Naciones Unidas para los Refugiados (ACNUR). Son referencias que provocan una reacción emocional poderosa.

Mientras, la memoria de los vencedores de la guerra ha ido reaccionando con estupor al avance político, social e ideológico de sus antiguos enemigos y también ha hecho sus movimientos estratégicos en el tablero de juego de las legitimidades y las venganzas, utilizando unas herramientas que durante siglos ha empleado con maestría: el poder de los santos. Las transformaciones en la interpretación que la derecha española da a su sufrimiento durante el conflicto han sido primero alentadas, y después abiertamente favorecidas por una política vaticana ${ }^{25}$ que ha visto en el martirio, en tanto que militancia activa por el ideario católico en un mundo que se percibe como cada vez más «relativista», un ejemplo a seguir en la lucha por el modo cristiano de entender el mundo. El ecumenismo cristiano permite, a su vez, a los sectores más radicales de la extrema derecha española convertir sus reivindicaciones políticas en legítimos conflictos de fe, alejándose de terrenos ideológicos menos aceptables para la opinión pública moderada, y recuperando terreno en aquella en la que tienen la máxima competencia: la educación religiosa.

Si bien en los manuales de ciencias sociales el papel de la Iglesia como motor e intérprete de la sociedad se ha visto enormemente reducido, el enorme avance que la enseñanza religiosa ha tenido en los últimos años en el sistema educativo nos habla de una exitosa estrategia que ha conseguido beatificar hasta el presente a bastantes más de 1.500 mártires de la Guerra Civil, y que ha culminado en la publicación en el Boletín Oficial del Estado de 24 de febrero de 2015 de un currículum académico profundamente conservador para la asignatura de religión de primaria y secundaria.

El 29 de marzo de 1987 Juan Pablo II beatificó en Roma a las tres primeras mártires de la guerra: tres monjas carmelitas descalzas que sufrieron martirio en Guadalajara, contradiciendo los deseos de la mayoría de la curia española y dando alas a la corriente conservadora que, en años posteriores, ocuparía los más altos puestos de poder en la Iglesia española. Dado el volumen de causas de beatificación que estaban en proceso (se estima que

${ }^{25}$ La política que seguirá al respecto el nuevo papa Francisco puede variar esta tendencia, pero todavía es pronto para saberlo. 
pueden llegar a unas 17.000), la Santa Sede decidió abrir en enero de 2001 una oficina estable en Madrid para que se encargase de la gestión y coordinación de las causas de los santos. Entre sus funciones se encuentra también la publicidad de las mismas, la publicación de bibliografía al respecto y la elaboración de material didáctico.

Uno de los aspectos prioritarios de esta última labor se centra en mostrar a los mártires como personas cercanas, normales y corrientes, narrativizando sus vidas para que sirvan de atractivos modelos a los fieles, especialmente a los niños. Tal y como decía, en 2007, Martí Alanis en su texto «Hablar hoy de la persecución religiosa en España»,

estas vidas ejemplares serán de un enorme valor educativo; no habrá doctrinas expresadas en palabras que puedan sustituirlas. Una vida ejemplar es una invitación a la imitación. [...] Ya no valen las hagiografías de los santos tradicionales, sin someterlas a una crítica histórica que, a veces, ha sido demoledora. No valen las más recientes si no se parte de un conocimiento emocional bien fundado y realista, en que aparezca la fragilidad humana y la veracidad histórica. Por lo que se refiere a nuestros mártires contamos con una limitación: la forma repetida en que dieron sus vidas en una misma persecución puede ceder a la rutina y caer en la insignificancia. Creo que debemos preocuparnos de este problema. Encontrar narraciones que interesen. El género narrativo es una forma humana y práctica de hacer teología. ${ }^{26}$

La Iglesia veía necesario, a través de este procedimiento, dar ejemplos de personas que hubieran llevado un estilo de vida radicalmente cristiano frente a lo que Benedicto XVI ha llamado la «dictadura del relativismo», para hacer explícitos sus planteamientos de que otro tipo de catolicismo, más activo y militante, era necesario en la sociedad española tal como apuntaba Blázquez Pérez, vicepresidente de la Conferencia Episcopal:

Jesús es el mártir por excelencia y cabeza de los mártires; este aspecto debe estar siempre presente a la hora de comprender la radicalidad y el sentido del martirio cristiano. Somos discípulos de Jesús que murió perseguido, condenado como malhechor, subversivo y blasfemo, y que fue resucitado por Dios. [...]

\footnotetext{
26 José Martí Alanis, «Hablar hoy de la persecución religiosa en España», en El martirio cristiano. Testimonio y profecía, ed. Encarnación González Rodríguez (Madrid: EDICE, 2007), 107-108. Esta es la editorial de la Conferencia Episcopal Española. Martí Alanis fue obispo de Urgell y copríncipe de Andorra de 1971 a 2003, así como creador de varios medios de comunicación católicos.
} 
En nuestra sociedad existe actualmente una especie de retraimiento vergonzante por parte de los cristianos para manifestarnos con sencillez como tales. Llama la atención que a veces alardeemos de lo que deberíamos ruborizarnos, y en cambio nos avergoncemos de los que deberíamos gloriarnos. [...] ¿Por qué esta situación tan poco «martirial»? Aparte de que el recato aconseja sobriedad a la hora de manifestar las convicciones religiosas, puede estar influyendo también en este campo la cultura de la modernidad. En efecto, la modernidad ha escindido, o pretende escindir, la vida de los hombres entre privada y pública, rigiendo en ésta lo que se llama «razón funcional»y a la vida privada se dejaría espacio para expresar la subjetividad creyente y otros sentimientos personales. Pero con esta separación la fe queda recluida en la conciencia, en la «privacidad» y en las «sacristías», y por otra parte, la vida pública se vacía de símbolos y de resortes espirituales, auténticos generadores de calidad moral y de humanización. Esta situación, con la que se desearía propiciar la convivencia en la pluralidad, no es sana. La tolerancia civil no puede reclamar silencio de lo esencial, indiferencia de los valores profundos y ocultación de la propia identidad; sí exige ciertamente respeto al que piensa de forma distinta y diálogo paciente, ya que la verdad no se defiende adecuadamente con la represión y la violencia. [...] El cristiano debe desenmascarar, combatir y en la medida de sus fuerzas evitar que tomen cuerpo propuestas moralmente indignas; si a las personas debe siempre amar, las conductas y leyes inmorales debe denunciar, $\mathrm{y}$, aunque a veces tenga que tolerarlas, no se debe confundir tolerancia y convalidación ética.

El martirio de miles de sacerdotes, religiosos, religiosas, obispos y seglares de España son para nosotros un signo y una apelación, una gracia y un imperativo. Si ellos mantuvieron la fidelidad en una situación límite, ¿qué haremos quienes vivimos ahora en la fácil flacidez de la libertad, del ocio? ¿O es que son más sutiles y seductoras las tentaciones de cada día que las que nos sobrevienen cuando nos es pedido todo? [...]. El Nuevo Testamento insiste en que el testimonio de Jesús fue público y solemne. Si los mártires se hubieran limitado a reconocer al Señor en el santuario de su conciencia, no habrían corrido peligro, ni hoy celebraríamos su triunfo y su gloria. ${ }^{27}$

27 Ricardo Blázquez Pérez, «¿Quién es un mártir cristiano?», en El martirio cristiano. Testimonio y profecía, ed. Encarnación González Rodríguez (Madrid: EDICE, 2007), 42-46. Blázquez Pérez era entonces el Presidente de la Conferencia Episcopal Española, además de obispo de Bilbao. 
Como muestra de estas creaciones destinadas a jóvenes y niños se encuentran algunas series de animación dedicadas a las vidas de mártires y beatos, como Santa Perpetua o el propio papa Juan Pablo II;28 y también cómics específicos y material didáctico diseñado por la Oficina Española de las Causas de los Santos para explicar la persecución religiosa. De estos dos últimos, se aportan a continuación algunos ejemplos.

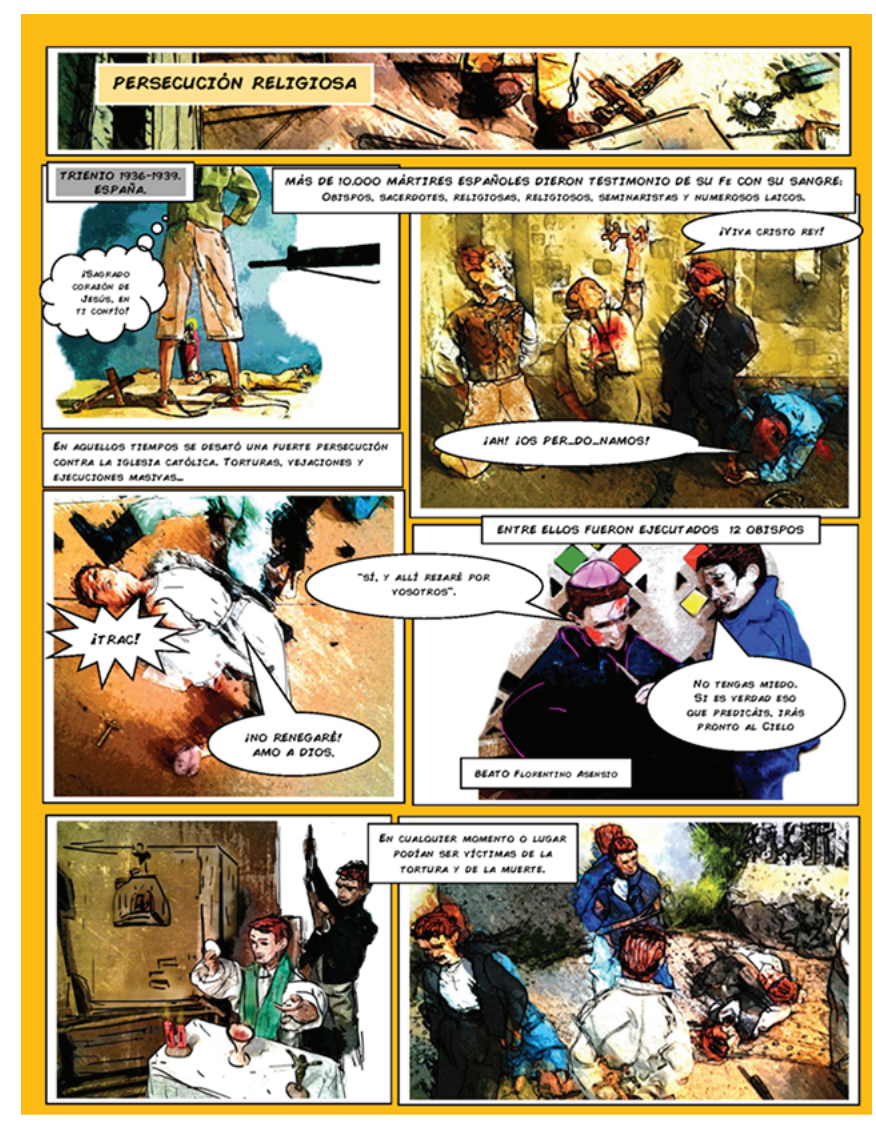

Figura 1. Cómic sobre la persecución religiosa promovido por la Oficina para la Causa de los Santos, publicado en 2014. Es consultable en http://www.religionenlibertad.com/ los-martires-en-comic-40562.htm, página creada por el sacerdote Jorge López Teulón, postulador de la Causa de los Santos de Castilla-La Mancha [consulta del 7 de marzo de 2015]. En dicha página no se indica autor ni editorial.

${ }^{28}$ Se pueden encontrar numerosas producciones similares disponibles en YouTube tecleando «Héroes de la Fe» o «Dibujos animados mártires» [consulta del 7 de marzo de 2015]. 

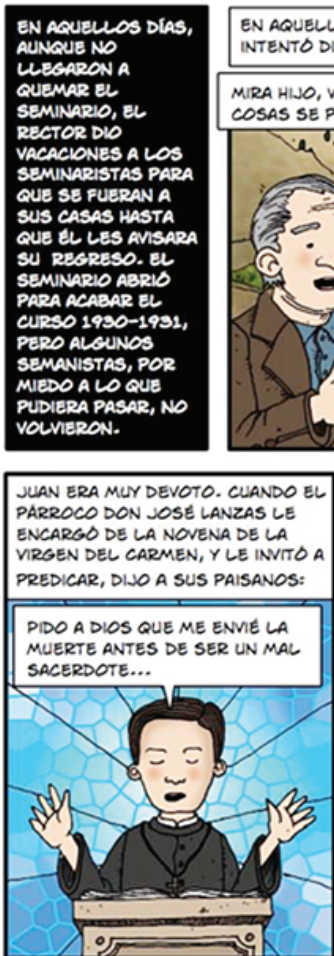
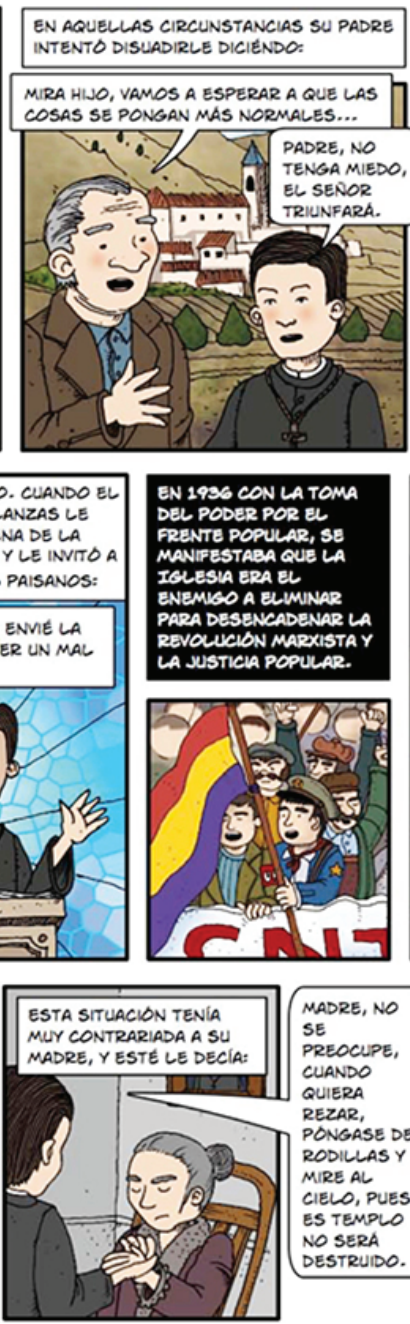

MADRE, NO SE PREOCUPE, CLANDO REZAR, PONGASE DE RODILLAS MIRE AL CIELD, PUES ES TEMPL DESTRUIDO.
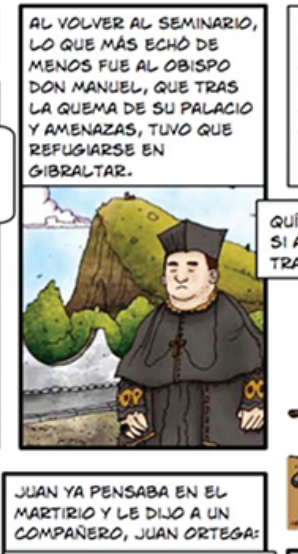

\section{ORTEGUTA, NO SE SI YO \\ TENDRLA FUERZA PARA}

SOPORTAR EL MARTIRIO, SI SE PRESENTA LA OCASION.

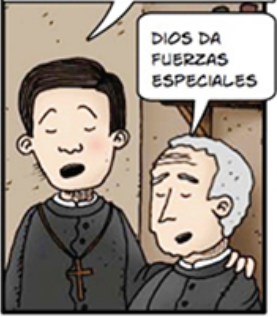

ESTA PENA QUEDO

REFLEJADA EN LA

CARTA QUE ESCRIBIO A

DON MANUEL EL 2 DE

JUL1O DEL 1935 EN LA

CELEBRACION DE

SUBDIACONO, Y QUERIA

PEDIR AL SENOR:

QUITAME ANTES LA VIDA

SI ALGÚN DIA HE DE SER

TRAIDOR DE LA IGLESIA.

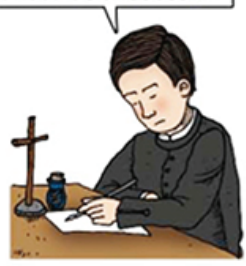

A JUAN LE LLEGARON

MALAS NOTICLAS DE

YUNQUERA, Y LE DWO A

FRANCISCD ESPINOSA

EL 16 DE JULIO.
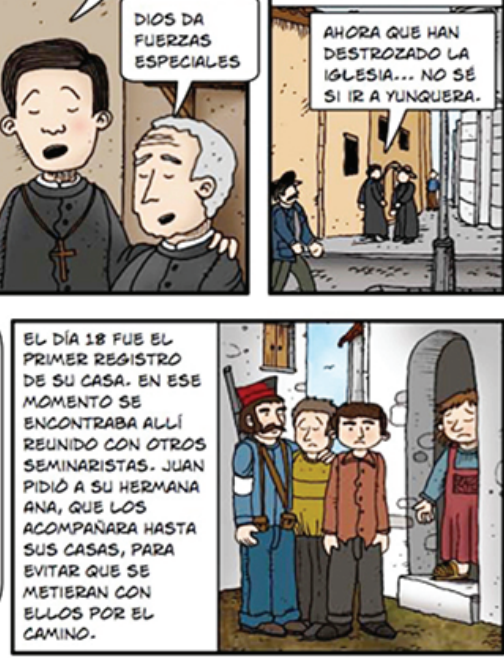
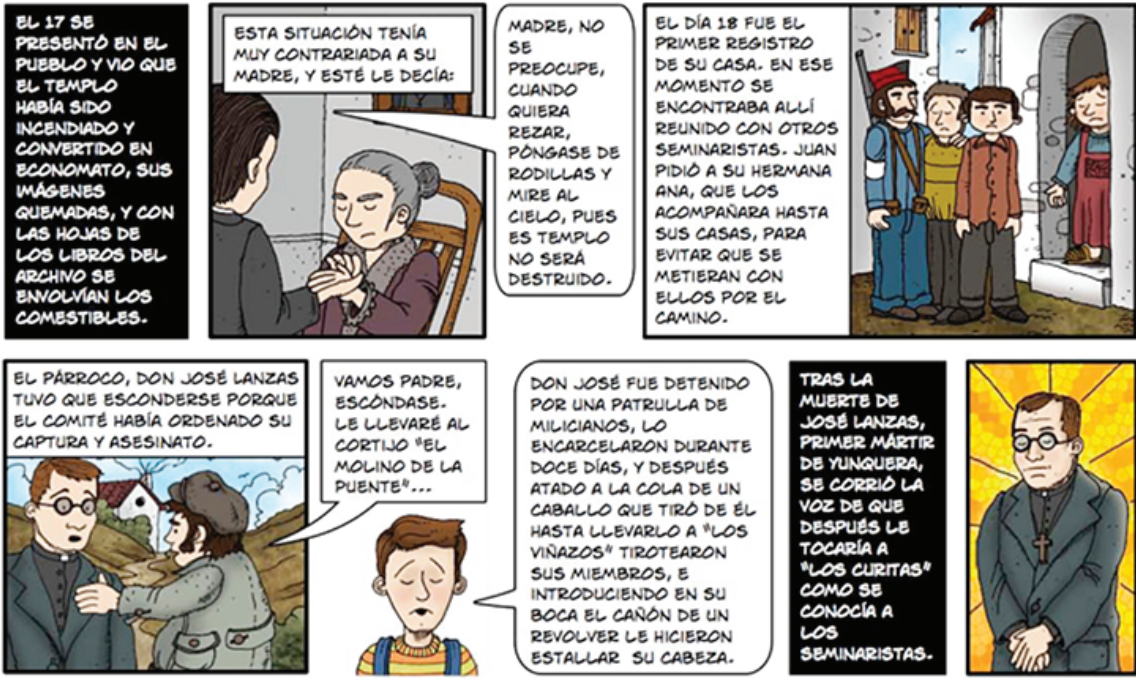

Figura 2. Pedro Sánchez Trujillo (guión) y Raquel Bernal y Curro Cervantes (dibujos), Juan Duarte Martín (Málaga: Diócesis de Málaga, 2012). Publicado para celebrar el centenario del nacimiento del beato. 


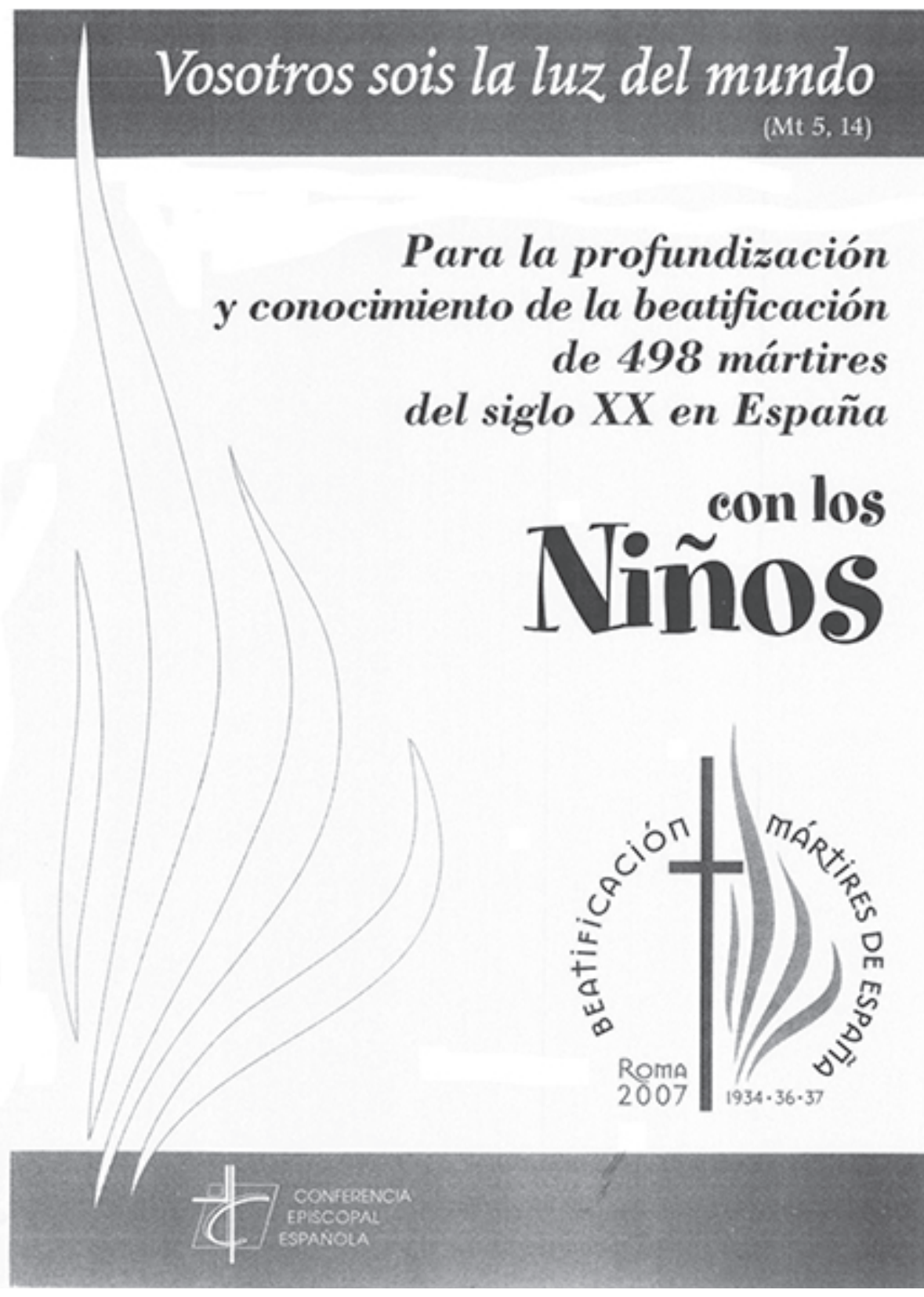

Figuras 3 y 4. Material didáctico, publicado en 2007, para explicar a los niños el motivo de una de las beatificaciones masivas de mártires de la guerra civil española.

Este texto para las catequesis con niños es consultable en la página http://www.archimadrid.es/martires498/page/13/ [consulta del 3 de octubre de 2009]. 


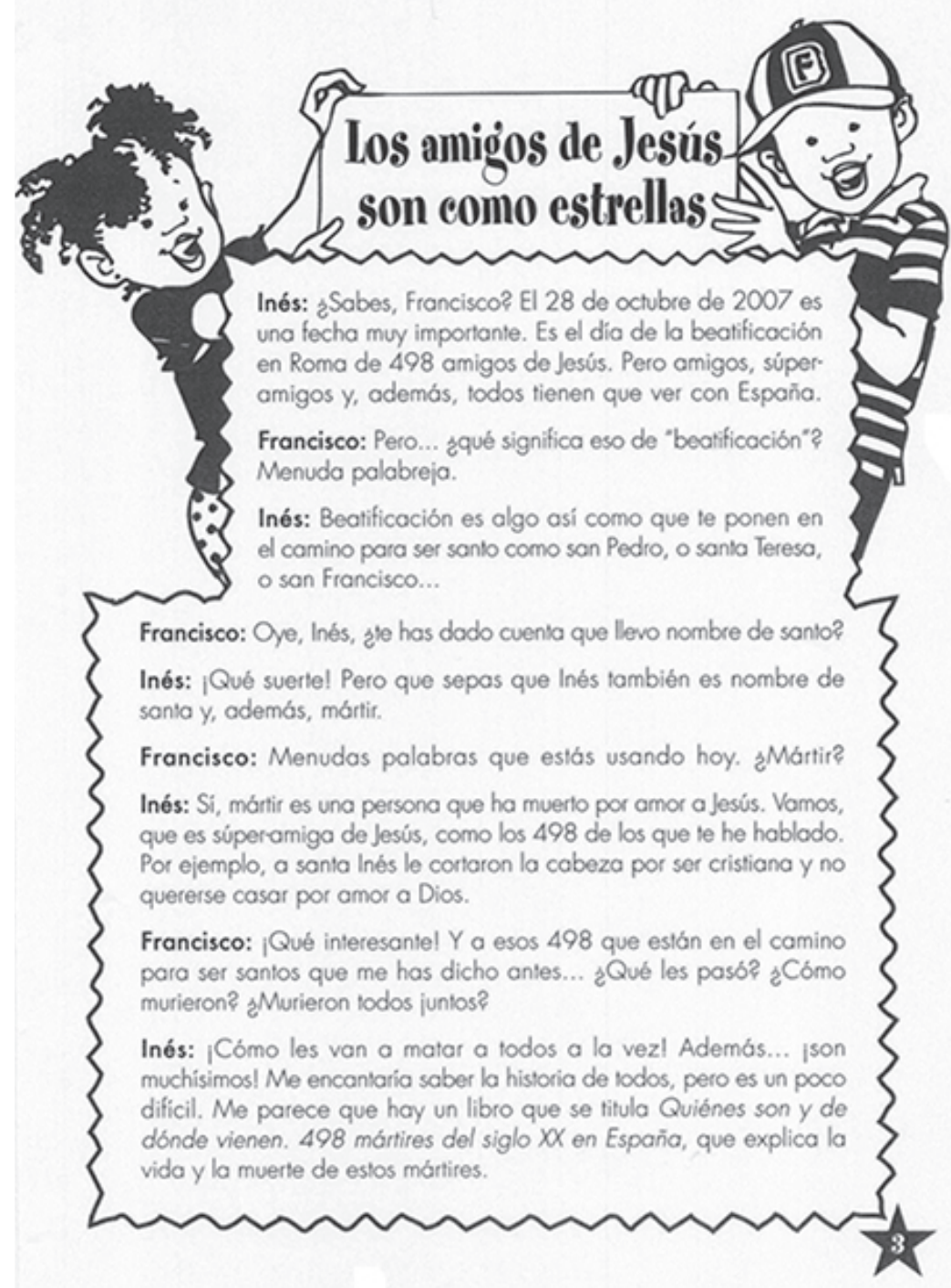

Esta iniciativa de la Iglesia ha supuesto la relectura por parte de sectores conservadores de su propio pasado en términos religiosos. Si al finalizar la Guerra Civil todos los que murieron en el bando vencedor —sacerdotes o laicos- eran considerados «caídos por Dios y por España y su revolución nacional-sindicalista», en el presente la vertiente política de la contienda se ha ido dejando poco a poco en el olvido, para recordarse fundamentalmente como una matanza de cristianos por parte de ateos. 
Las constantes referencias al valor de la amistad infantil, que podemos observar tanto en el texto de la figura 4 como en el nuevo currículo de la enseñanza de la religión en las escuelas, nos muestran un camino emocional bien trazado.

Todavía es demasiado pronto para conocer las implicaciones de este planteamiento en la disputa por captar el entusiasmo, siempre movilizador, de las jóvenes generaciones españolas. Se trata de una propuesta que puede ser bastante atractiva para una juventud en busca de ideales, teniendo en cuenta que puede ser reforzada desde los púlpitos de las iglesias. A día de hoy, las parroquias españolas se están llenando de reliquias de estos nuevos beatos y santos, y su conmemoración empieza a asociarse al ciclo festivo de numerosos pueblos (no hay que olvidar que los religiosos murieron en la mayoría de los casos muy al principio de la guerra, en el verano del 36). Son intermediarios cercanos entre el cielo y la tierra, con familias conocidas del mismo barrio que los fieles.

Esta irrupción de una emoción religiosa martirial en la cotidianidad de las escuelas y de las misas dominicales está pasando muy desapercibida para los profesionales de la docencia y para los defensores de la escuela laica. Habrá que esperar algunos años para ver las consecuencias de este modelo en la España futura.

\section{Nota sobre la autora:}

María García Alonso es profesora del departamento de Antropología Social y Cultural de la Universidad Nacional de Educación a Distancia de España (UNED), doctora por el mismo departamento y licenciada en Geografía e Historia (especialidad Antropología de América) por la Universidad Complutense de Madrid. Actualmente es Vicerrectora de Formación Permanente de la UNED, miembro de la Junta directiva del Centro Internacional de Memoria y Derechos Humanos (CIEMEDH) de la UNED y presidenta de la Red Internacional de Estudios de Territorio y Cultura (RETEC). 
Ha estudiado las relaciones entre la antropología y la historia, especialmente a través de la reconstrucción de la memoria colectiva de los actores sociales ya sea a través del trabajo de campo o de recursos archivísticos. Sus preocupaciones teóricas se complementan con su interés por formas alternativas de presentación de los resultados de las investigaciones, en varios niveles de lectura, que permitan tanto la participación de los protagonistas sobre los procesos vividos, como el debate académico. Ha sido comisaria entre otras de las exposiciones Las Misiones Pedagógicas (1931-1936) en el Cuartel del Conde Duque (Madrid) y otras ciudades (2006-2007) y Las Misiones Sociopedagógicas entre España y América: México-España-Uruguay (Montevideo, 2009). 